\title{
Research Productivity Among Recipients of AAFP Foundation Grants
}

\author{
Martin C. Maboney, $M D, P b D^{1,2,3}$ \\ Puja Verma, MSPH \\ Susie Morantz, BS ${ }^{4}$ \\ 'Department of Family Medicine, School of \\ Medicine and Biomedical Sciences, State Uni- \\ versity of New York at Buffalo, Buffalo, NY \\ ${ }^{2}$ Division of Cancer Prevention \& Popula- \\ tion Sciences, Roswell Park Cancer Insti- \\ tute, Buffalo, NY \\ ${ }^{3}$ Department of Social \& Preventive Medi- \\ cine, School of Public Health \& Health \\ Professions, State University of New York \\ at Buffalo, Buffalo, NY \\ ${ }^{4}$ American Academy of Family Physicians \\ Foundation, Leawood, Kan
}

Conflict of interest: Dr. Maboney has previously served as a member of the Joint Grant Awards Program (JGAP) Review Council and continues as an external reviewer. Ms. Morantz serves as manager for the JGAP.

\section{CORRESPONDING AUTHOR}

Martin C. Mahoney, MD, PhD

Division of Cancer Prevention and

Population Sciences

Roswell Park Cancer Institute

Elm and Carlton Streets

Buffalo, NY 14263

martin.mahoney@roswellpark.org

\begin{abstract}
PURPOSE This study examines research productivity generated by the American Academy of Family Physicians (AAFP) Foundation and the AAFP Joint Grant Awards Program (JGAP) based upon projects funded during the period 1990 through 2000.

METHODS A structured questionnaire was mailed to all JGAP applicants who were funded between 1990 and $2000(N=95)$. The cross-sectional questionnaire included items reflective of research productivity: (1) numbers of publications, (2) numbers of presentations, and (3) numbers and types of subsequent grants. An additional comparison examined publication productivity among a subset of funded $(n=17)$ and nonfunded applicants $(n=36)$.
\end{abstract}

RESULTS The 69 funded respondents reported 91 publications and 129 presentations deriving from JGAP-supported research; 26 subsequent grants were funded (\$9.6 million total costs). Funded and nonfunded applicants showed a significant increase in the overall number of publications during the 5 -year period after their application when compared with the 5 -year period before their application. Funded applicants had a greater number of publications during both the 5 years before and the 5 years after their JGAP grant submission.

CONCLUSION Projects supported by the JGAP have generated a considerable body of publications and presentations, as well as subsequent grant activity. This program appears to be important in supporting the early career development of family medicine researchers.

Ann Fam Med 2006;5:143-145. DOI: 10.1370/afm.628.

\section{INTRODUCTION}

he Joint Grant Awards Program (JGAP), jointly supported by the American Academy of Family Physicians (AAFP) Foundation and the AAFP, represents a unique resource for early career family medicine researchers with its focus on supporting smaller-scale projects (1 year of support and less than $\$ 25,000$ ). This program supports efforts to expand the numbers of researchers examining issues related to the science of family medicine based upon physician-patient interactions within the context of families, communities, and health care systems. ${ }^{1,2} \mathrm{~A}$ survey was undertaken to examine the outcomes of the JGAP based upon projects funded during the period 1990 through 2000.

\section{METHODS}

The sample for this survey included 95 applicants to the JGAP who were awarded research funding during an 11-year period; 83 applicants received 1 award, 11 applicants received 2 awards, and 1 applicant received 3 awards, for a total of 108 funded projects. We sent these applicants a structured questionnaire that was mailed in March 2003; 2 additional 
mailings went to nonrespondents after 4 and 7 months. Applicants who received awards for pilot projects, including Research Stimulation Grants and awards to residents, were excluded from this analysis.

Survey items gathered information on number of JGAP submissions and number of JGAP grants received, as well as list of publications, presentations, and subsequent grants submitted based on data related to JGAP-supported projects. We asked respondents to include a current copy of their curriculum vitae with the completed form.

Using descriptive statistics, we summarized research productivity, defined as scientific publications, research presentations, and subsequent grant submissions developed as a result of the JGAP-funded project.

In an additional analysis, we compared publications among respondents who received JGAP funding between 1996 and $2000(\mathrm{n}=17)$ with a sample of nonfunded applicants $(\mathrm{n}=36)$ during these same years. We reviewed the PubMed database to identify publications for the 5 years before and 5 years after the JGAP application; curriculum vitae were reviewed to confirm publications. Median numbers of publications before and after JGAP funding were compared using the Wilcoxon signed-rank test, and the funded and nonfunded groups were compared using the Mann-Whitney $U$ test.

\section{RESULTS}

The mailed questionnaire achieved an overall response rate of $73 \%$ (69 of 95 awardees). These 69 respondents accounted for $76 \%$ of the grants funded between 1990 and 2000 (82 of 108 funded projects). Seventyfive percent of respondents were male; nearly all respondents were family physicians, and about one half reported an advanced academic degree (masters or doctorate) in addition to their medical degree.
With regard to research productivity resulting from a JGAP-funded project, respondents generated a total of 91 peer-reviewed publications (median 1; range, 0-6) to their JGAP projects. Overall, $71 \%$ had published at least 1 journal article. Of note, $75 \%$ of the papers were published in a primary-care-oriented journal, with $64 \%$ (58/91) appearing in a family medicine journal. Also reported were a total of 129 presentations resulting from a JGAP-funded project (median 1; range, 0-12), with common venues being meetings of the North American Primary Care Research Group, the Society for Teachers of Family Medicine, and the AAFP annual Scientific Assembly. The JGAP-funded projects generated a total of 39 grant applications submitted to the National Institute of Health $(\mathrm{n}=20)$, to nonfederal agencies and organizations $(\mathrm{n}=17)$, and to the AAFP $(n=2)$. Among these 39 submissions, 26 were funded, yielding $\$ 9.6$ million in funding support. Several respondents reported multiple submissions and multiple funded projects.

As displayed in Table 1, among the persons who applied between 1996 and 2000, funded applicants had a greater number of publications during the 5 years before submission than did the nonfunded applicants (median of 3 publications vs 1 publication, $P=.039$ ). During the 5 years after submission of their application, applicants who received JGAP funding had a median of 7 publications compared with a median of 3.5 among nonfunded applicants $(P=.010)$. Both funded and nonfunded applicants showed a significant increase in the median number of publications when the 5-year period before application submission was compared with the 5 -year period afterward ( $P$ values are displayed in the table). We also computed a differences score (defined as the number of publications 5 years after the JGAP application submission minus the number of publications 5 years before) for each subject. An analysis using the Mann-Whitney $U$ test found that the differences score did not vary by funding status.

\section{Table 1. Number of Publications by Joint Grant Awards Program (JGAP) Applicants Before and After Application, by Funding Decision}

\begin{tabular}{|c|c|c|c|c|c|c|}
\hline & \multicolumn{2}{|c|}{$\begin{array}{l}\text { Funded Applications } \\
\qquad(\mathrm{n}=17)\end{array}$} & \multicolumn{2}{|c|}{$\begin{array}{l}\text { Non-JGAP-Funded Applications } \\
\qquad(n=36)\end{array}$} & \multirow[b]{2}{*}{ P Value* } & \multirow[b]{2}{*}{$P$ Value $^{\dagger}$} \\
\hline & $\begin{array}{c}5 \text { Years Before JGAP } \\
\text { Application (a) }\end{array}$ & $\begin{array}{l}5 \text { Years After JGAP } \\
\text { Application (b) }\end{array}$ & $\begin{array}{l}5 \text { Years Before JGAP } \\
\text { Application (c) }\end{array}$ & $\begin{array}{l}5 \text { Years After JGAP } \\
\text { Application (d) }\end{array}$ & & \\
\hline Mean (SD) & $4.9( \pm 1.3)$ & $9.1( \pm 1.6)$ & $2.7( \pm 0.7)$ & $4.4( \pm 0.7)$ & & \\
\hline Median & 3 & 7 & 1 & 3.5 & .039 (a vs c) & .010 (b vs c) \\
\hline Range & $0-19$ & $0-20$ & $0-19$ & $0-20$ & & \\
\hline$P$ value & \multicolumn{2}{|c|}{.009 (a vs b) $)^{\ddagger}$} & \multicolumn{2}{|c|}{$.010(\text { c vs } d)^{\ddagger}$} & & \\
\hline \multicolumn{7}{|c|}{ Note: includes JGAP applicants 1996-2000. } \\
\hline \multicolumn{7}{|c|}{$\begin{array}{l}\text { * } P \text { value based on Mann-Whitney } U \text { test comparing median publications } 5 \text { years before application, funded vs nonfunded applicants. } \\
\dagger P \text { value based on Mann-Whitney } U \text { test comparing median publications } 5 \text { years after application, funded vs nonfunded applicants. } \\
\text { † } P \text { value based on Wilcoxon signed-rank test comparing median publications } 5 \text { years before vs } 5 \text { years after JGAP application. }\end{array}$} \\
\hline
\end{tabular}




\section{DISCUSSION}

Similar to approaches used elsewhere, ${ }^{3,4}$ we defined research productivity in our study based on objective measures, such as publications, presentations, and grant activity. An evaluation of the Grant Generating Project (GGP), a program supported by the "family" of family medicine organizations and the departments of participants, concluded that the GGP is successful based on the substantial number of grant submissions by participants. The GGP evaluation, however, did not offer any comparisons with a group of nonparticipants, nor did it assess publication yield.

Our analysis suggests that the JGAP has aided the development of successful senior and mid-career family medicine researchers by serving as a foundation upon which to build a research career. The numbers of publications, presentations, and grant applications derived from JGAP-supported research projects suggests JGAP plays a positive role in the development of family medicine researchers. Early career publications are a common element noted across models found to be predictive of faculty research productivity. ${ }^{4,6,7}$

Although the survey response rate was reasonable and compares favorably with similar evaluation efforts, it is possible that response bias might have influenced these findings. We noted no difference in response rates or productivity based on time period of initial funding. Our survey instrument did not collect information on percentage of time spent on research activities, the impact of mentoring, research environments, or intrinsic factors motivating research interest and productivity. Finally, the limited numbers of grant awards in any single year necessitated that we expand the study period to include multiple years.

Total research monies awarded by the JGAP between 1990 and 2000 amounted to $\$ 1.2$ million. The $\$ 915,202$ received by the 69 respondents to this study generated $\$ 9.6$ million in subsequent funded research projects, yielding a return on investment exceeding tenfold.

In conclusion, the results of this survey provide evidence that the JGAP is achieving a positive out- come based on significant increases in the overall numbers of publications after JGAP funding. The JGAP program appears to support the career development of successful applicants. In addition, the program serves as a valuable resource by generating pilot data leading to subsequent grant submissions. Both efforts contribute to establishing an academic base for the discipline of family medicine. It is hoped that sustained funding support, from both AAFP and the AAFP Foundation, will be maintained along with efforts to promote applications from early career investigators.

To read or post commentaries in response to this article, see it online at http://www.annfammed.org/cgi/content/full/5/2/143.

Key words: Financing, organized; research/funding; program review; research capacity building; faculty, family practice

Submitted August 18, 2004; submitted, revised, May 29, 2006; accepted July 8, 2006.

Acknowledgments: We are grateful for the input we received from colleagues on the content of this article. We acknowledge the contributions of JGAP reviewers, members of the Joint Grant Awards Council, and AAFP Foundation program staff for their efforts in reviewing project submissions.

\section{References}

1. Culpepper L, Franks P. Family medicine research. Status at the end of the first decade. JAMA. 1983;249(1):63-68.

2. Stange KC, Miller WL, McWhinney I. Developing the knowledge base of family practice. Fam Med. 2001;33(4):286-297.

3. Godkin MA. A successful research assistantship program as reflected by publications and presentations. Fam Med. 1993;25(1):45-47.

4. Mavis B, Katz M. Evaluation of a program supporting scholarly productivity for new investigators. Acad Med. 2003;78(7):757-765.

5. Campbell JD, Longo DR. Building research capacity in family medicine: evaluation of the Grant Generating Project. J Fam Pract. 2002;51(7):593.

6. Weiss BD. Publications by family medicine faculty in the biomedical literature: 1989-1999. Fam Med. 2002;34(1):10-16.

7. Bland CJ, Wersal L, VanLoy W, Jacott W. Evaluating faculty performance: a systematically designed and assessed approach. Acad Med. 2002;77(1):15-30. 